\title{
Realidades del empoderamiento de las mujeres afrodescendientes en Colombia
}

Laura Alejandra Prieto Forero

Karen Lizeth Sotelo VelásQuez

María Camila Zabala Merchán ${ }^{\mathrm{I}}$

\section{Introducción}

La población afrocolombiana pertenece a las comunidades descendientes de las personas africanas esclavizadas por los españoles. Esta se denomina africana gracias a su ancestro cultural, espiritual y étnico asumiéndola como un valor tradicional y personal. Ahora bien, raíz de la expedición de 1851 con la ley de libertad de los esclavos, se logró abolir de manera legal la esclavitud de las personas. A pesar de esto, los afrocolombianos fueron excluidos por parte del Estado ya que no eran sujetos de derechos y así mismo, fueron excluidos por el ordenamiento jurídico.

Aun así siendo pobladores de Colombia, durante 70 años esta comunidad no hacia parte de la ciudadanía. Poco a poco, durante varios periodos, los intereses políticos se transformaron y empezaron a hacer parte del proyecto nación que duró desde 1852 hasta 1991. Allí por primera vez la Constitución Política los reconoce como sujetos jurídicos con derechos favoreciendo a la comunidad.

1 Estudiantes de la Facultad de Comunicación Social de la Universidad Santo Tomás. 
Con la firma de la Asamblea Nacional Constituyente en Colombia en 1991, se marca uno de los hitos históricos más importantes en el país, que transformó no solo las formas de relación macropolítica sino también las relaciones micropolíticas, que en últimas conformaron al país.

A raíz de esto en Colombia se creó un escenario de diversas movilizaciones con el fin de abrir nuevos caminos en la vida política de comunidades excluidas. Allí hubo la participación de varias organizaciones sociales y ONG que tenían como objetivo buscar la representación y participación de la asamblea. Las luchas que se han iniciado entorno a la participación de la comunidad afro en el país han sido extensas, pasando por procesos de definición, autoformación, búsqueda del reconocimiento social, entre otras.

Ahora bien, desde 1791 con la declaración de los derechos de la mujer se inicia un nuevo espacio que se configura dentro de la participación en las esferas públicas cotidianas. En este sentido los procesos de organización de las mujeres afro partieron de nuevas iniciativas estatales y a la vez gubernamentales donde se tenía como fin vincular a las mujeres en el desarrollo de la participación y el reconocimiento político. Es decir, empezar a generar acciones que incidan en cierto grado sobre asuntos del Estado frente a la exclusión de la mujer afro dentro de los procesos sociales, políticos y culturales. A raíz de estas acciones se permite realizar una reivindicación de género y etnia en el desarrollo cultural y político. No solo se ejercen las luchas feministas por la participación e inclusión sino también la participación de las etnias en un proceso que cumple con el objetivo de desescalar los procesos etnocéntricos. Esto permite generar procesos de definiciones y redefiniciones sobre las esferas públicas y esferas privadas, de colectivos e individuos.

Gracias a los fortalecimientos que se dieron en los últimos años, las mujeres afro logran acceder a cargos de elección popular. Además, hoy en día se pretende crear agendas públicas sobre los mecanismos que permitan generar colectivismo entre la comunidad afro que nutra la articulación con otros colectivos que produzca visibilización y empoderamiento. Este colectivismo se ve representado en los discursos ya que estos están inmersos en un escenario de lucha en pro a los derechos, intereses y políticas culturales que toman un grado de importancia en 
la comunidad afrocolombiana. En definitiva, las mujeres afrocolombianas participan políticamente con el fin de crear posturas que brinden protección a sus derechos étnicos y de territorio.

La posición política en las mujeres afro de cierta manera es difícil, puesto que se enfrentan a escenarios completamente diferentes como la exclusión y la inclusión y así mismo la hegemonía que a la vez les impide participar en ámbitos públicos e institucionales. En este sentido, el patriarcado es una de las formas más comunes que existe para ejercer poder sobre la mujer. Pero a partir de las resistencias, las mujeres crean modos de adaptación que las conlleva a generar espacios que les permite fortalecer su perspectiva de género, iniciando procesos de reconocimiento de su propia identidad y al mismo tiempo de su comunidad.

\section{Entrando en contexto}

La participación política es uno de los términos que se relacionan directamente con el ejercicio y la concepción de la democracia. Es decir, para que un sistema democrático sea eficiente y legítimo necesita de la participación ciudadana en tanto es el método idóneo para la toma de decisiones que encaminen los acontecimientos políticos en pro del desarrollo y crecimiento social (Subgerencia Cultural del Banco de la República, 2015, p. 1).

Ahora bien, es importante aclarar que la participación política no solo se limita a la ejecución del voto en procesos electorales, se trata, también, de la acción ciudadana en miras de la construcción de políticas de gobierno que estructuren dinámicas ecuánimes en cuanto a la organización social, política, económica y cultural de un país.

En Colombia, luego de la instauración de la Constitución Política de 1991, se abrió paso a un mayor protagonismo de la sociedad civil en cuanto al establecimiento de derechos y deberes que le permitieran incidir en la vida política del país; de igual forma se primó el reconocimiento de las comunidades étnicas como sujetos políticos de las nuevas dinámicas nacionales. De hecho, según Rivas (2011), fue a partir de dicha constitución que la comunidad afrodescendiente empezó a 
existir políticamente en el país, siendo reconocida como minoría con participación en el Congreso de la República.

Si bien, este reconocimiento significó la construcción de un país democrático con amplia participación étnica y ciudadana, el empoderamiento de la mujer como sujeto político dentro de la gobernanza democrática nacional siguió estando relegado. Según ONU Mujeres Colombia (2015), ninguna sociedad, en la actualidad, ha logrado la plena participación de las mujeres, ni ha logrado reconocer y potencializar su liderazgo y representar sus agendas y necesidades en las políticas públicas.

Las mujeres constituyen la mitad de la población en todos los países. Apartar a las mujeres y excluirlas de la participación en la vida política, social, económica y cultural significaría, de hecho, tanto como privar a la población de cualquier comunidad de la mitad de sus capacidades. Shirin Ebadi, abogada y activista iraní. ONU Mujeres Colombia (2015)

De aquí radica el interés del reconocimiento de la mujer afrodescendiente en Colombia como sujeto configurador de poder étnico y participación política autónoma, siendo herramientas idóneas para "plantear y difundir con claridad la problemática, los derechos, las reivindicaciones tanto de los pueblos afroamericanos, como en particular, de la propia mujer afroamericana" (Mosquera, Biblioteca vitual Luis Ángel Arango, 2012, p. 1).

Consecuentemente, es necesario realizar el análisis del empoderamiento femenino afro dentro de las esferas privadas y políticas, a partir de elementos cotidianos y, dentro de las dinámicas sociales, necesarios, tales como los medios de comunicación masiva, siendo una de las industrias culturales más representativas e influyentes en las realidades locales, nacionales e internacionales.

A partir del análisis de los discursos emprendidos por estos medios, se hace visible la concepción y la configuración de los discursos político-sociales que se tejen alrededor de la participación y la incidencia étnica profundizando en el elemento femenino, que, por ahora, ataña la reflexión.

Como bien plantea Campbell (2007), si bien es claro que el derecho a elegir y ser elegido, en la mayoría de los casos, se ha logrado; el 
derecho a tener espacios de poder reales para las mujeres afrodescendientes, que garanticen una verdadera representación, debe ser profundizado en los discursos sociales y masivos que propendan por la participación activa en pie de equidad de los ciudadanos, sin distingo de origen, clase y sexo (pp. 2-3).

De ahí la importancia del reconocimiento de las representaciones sociales, que desde los discursos mediáticos, se construyen alrededor del tema femenino afro, en miras a establecer análisis discursivos adoptados en los medios de comunicación que, si bien, establecen puntos de diálogo referentes al tema; se quedan cortos al momento de empoderar las acciones y participaciones afrodescendientes en la construcción de una Colombia democrática e incluyente.

\section{La metodología en la investigación}

Con el fin de dar cuenta de las representaciones sociales que propone el medio de comunicación escrita vía web, elespectador.com, sobre el papel de la mujer afrocolombiana en la política, se utilizó los Estudios Críticos del Discurso en un periodo de tiempo del 1 de enero del 2015 al 30 de abril del 2016, en tanto esta temporalidad comprende una exigencia nacional más fuerte de los movimientos sociales en los temas de la paz en la Habana, gracias también, a que el proceso de paz situado en la reserva de los temas y su negociación fue delimitado por el mismo presidente Santos.

En consecuencia, la investigación se encaminó en los discursos multimodales presentados por elespectador.com, entendiendo por estos "el campo de los estudios del discurso (...) al estudio del lenguaje en combinación con otros recursos tales como las imágenes, el simbolismo científico, la gestualidad, las acciones, la música y el sonido" (O’Halloran, 2012, p. 78).

Ahora bien, a través de elespectador.com se realizó la selección de 12 unidades de análisis que delimitaron los recursos y las estrategias en el corpus escogido. Básicamente, la investigación tuvo en cuenta dos fases para cumplir el objetivo general de la misma.

Por un lado, la primera fase constituyó en observar las frecuentes apariciones de las palabras relacionadas con las mujeres afro en 
la política y el contexto temático que antecede y procede a dichas palabras. De esta manera, se realizó un análisis cuantitativo de la cantidad de veces que se repitieron el término de "mujer", "política" y "afrocolombiana" con el fin de identificar los patrones de uso de los términos, a la vez que, mediante un análisis del contexto, se identificó cómo el uso de las palabras contribuyó a reconocer los elementos a los que aluden y a las representaciones sociales que se generan en torno a las mismas.

En una segunda fase, se identificaron y analizaron los recursos discursivos utilizados en el corpus escogido, entre las que se encontraron el uso de algunas figuras retóricas como la hipérbole, que contribuye a exagerar elementos en el texto y hacer énfasis en estos, la anáfora, que consiste en la repetición de una palabra o un conjunto de palabras, o la metonimia, la sustitución de una palabra por otra. La identificación de estas figuras retóricas constituye el reconocimiento de cómo el uso de un lenguaje metafórico cambia la comprensión de un panorama social y puede alejar o acercar al receptor de un entendimiento de la trascendencia de dicha temática.

A la vez, se identificaron otros recursos discursivos como la cuantificación que, en el caso específico de las mujeres afrocolombianas en la política, sí se puede interpretar de manera ambigua en tanto los números no representan realidad fáctica de participación ciudadana proactiva de la mujer. Otro recurso discursivo que se analizó es la polifonía en el discurso, esto debido al hecho de que muchas personas y entidades se manifestaron al momento de que fenómenos sociales, como la participación política de la mujer afrocolombiana, se convirtiera en el centro de una noticia y, el manejo de estas voces y opiniones, le dio a su vez un sentido propio al discurso que más adelante se explicará.

Por último, se evidenciaron las estrategias discursivas que se crearon a través del uso de los recursos anteriormente mencionados y son entendidas "como diferentes medios que usa un hablante para adquirir y comprender y reproducir el habla, para evaluar de manera eficiente el significado (...) de los enunciados en el discurso" (Pilleux, 2001, p. 20). Entre las estrategias discursivas se encuentra la espectacularización, la supresión, la nominalidad y la legitimidad. Estas cuatro estrategias han jugado un papel muy importante en los discursos en 
tanto se reconoce cómo hoy se nombran y se visibilizan a las mujeres negras inmersas en dicha panorámica política frente a la sociedad espectadora colombiana.

\section{Nuestros hallazgos}

En efecto, la investigación quiso, en una primera medida, encontrar las representaciones sociales de las mujeres negras en la política en un medio masivo como elespetador.com, en un periodo de tiempo de cambio de administración distrital. Sin embargo, y como primer hallazgo, se evidenció que dicha temática ni siquiera se tiene en cuenta en los diarios nacionales de forma constante, e incluso sin abordar la categoría del género. Se evidenció además, la carencia de noticias que contengan a la comunidad negra y la política, pese a todo el trabajo de los movimientos sociales de afrodescendientes en la capital.

No obstante, y bajo la consideración de un periodo de tiempo entre 1 de enero del 2015 al 30 de abril del 2016 a nivel nacional, se encontró que la constante a la hora de hablar de participación política siempre tiende a agrupar en la terminología etnia a los indígenas y los afro, por supuesto, obviando en todo momento la participación de la mujer, bien sea indígena o negra, en los procesos políticos. Todo lo anterior, fue evidenciado a través de las estrategias de nominalización encontradas en el corpus, y en el análisis de los co-textos de las palabras afrocolombianas, donde en la mayoría de casos se enunció en general, es decir, comunidades afrocolombianas. Esto supone políticamente una representación de unidad de peticiones y exigencia de garantías para los dos grupos étnicos, lo que por supuesto es un error, en tanto sus características fenomenológicas los hacen diferentes entre sí.

Por último, y gracias a que el corpus arrojó en su gran mayoría noticias sobre etnicidad general y participación política, se dedujo que las mujeres afro son entendidas en el discurso de elespectador.com solo para visibilizar las causas y consecuencias de la victimización que han sufrido las mismas en Colombia; sus relatos de conflictos sin resolver son las únicas formas de percibir su participación en la sociedad colombiana más no en la política, pues, a la hora de sentar la petición de participación, se cuenta únicamente con la presencia de voces 
masculinas indígenas y negras dentro de las realidades mediáticas y, por tanto, en las realidades sociales fácticas.

\section{Referencias}

Asamblea General de las Naciones Unidas. (2011). Resolución sobre la participación de la mujer en la política. Obtenido de resolución sobre la participación de la mujer en la política. Recuperado de: http://colombia. unwomen.org/es/como-trabajamos/liderazgo-y-participacion-politica\#sthash.PpDdTj2V.dpuf

Campbell, E. (2007). Liderazgo y participación política para las mujeres afrodescendientes. Women in the Americas: Paths to political power. BID.

Mosquera, J. d. (2012). Biblioteca vitual Luis Ángel Arango. Obtenido de Los grandes compromisos de la mujer afrocolombiana en nuestro tiempo. Recuperado de: http://www.banrepcultural.org/blaavirtual/sociologia/ etnoeducacion/etnoeducacion $0 . \mathrm{htm}$

Mosquera, J. d. (2014). Boletín del Movimiento Nacional Afrocolombiano Cimarrón: Estudios Afrocolombianos. La Población Afrocolombiana. Recuperado de: http://www.banrepcultural.org/blaavirtual/sociologia/ estudiosafro/estudiosafro3.htm

O’Halloran, K. L. (2012). Análisis del discurso multimodal. ALED, 144.

ONU Mujeres. (2015). Liderazgo y participación política. Recuperado de: http://colombia.unwomen.org/es/como-trabajamos/ liderazgo-y-participacion-politica

Rivas, A. (5 de Marzo de 2011). Cuestiones pedagógicas. Obtenido de Participación política afrodescendiente en Colombia:¿ Un sujeto político en construcción? Recuperado de: http://cuestionespedagogicas.blogspot. com.co/2011/03/participacion-politica-afrodescendiente.html

Sabucedo, M. (2015). Biblioteca Virtual Luis Ángel Arango. From Participación Política. Recuperado de: http://www.banrepcultural.org/blaavirtual/ ayudadetareas/politica/participacion_politica

Schuler, M. (2014 йил 16-Мауо). SEXOLOGÍA FEMENINA. ¿Qué es el Empoderamiento Femenino? Recuperado de: https://sexologiafemenina. wordpress.com/2014/05/16/que-es-el-empoderamiento-femenino/

Subgerencia Cultural del Banco de la República. (2015). Biblioteca Virtual Luis Ángel Arango. Obtenido de Participación Política. Recuperado de: http://www.banrepcultural.org/blaavirtual/ayudadetareas/politica/ participacion_politica 